This item was submitted to Loughborough's Research Repository by the author.

Items in Figshare are protected by copyright, with all rights reserved, unless otherwise indicated.

\title{
A formal asymmetric synthesis of both enantiomers of the Erythrina Alkaloid 3-Demethoxyerythratidinone
}

PLEASE CITE THE PUBLISHED VERSION

PUBLISHER

(C) Elsevier

LICENCE

CC BY-NC-ND 4.0

\section{REPOSITORY RECORD}

Allin, Steven M., Guy B. Streetley, Martin J. Slater, Stella L. James, and William P. Martin. 2019. "A Formal Asymmetric Synthesis of Both Enantiomers of the Erythrina Alkaloid 3-demethoxyerythratidinone". figshare. https://hdl.handle.net/2134/678. 
This item was submitted to Loughborough's Institutional Repository by the author and is made available under the following Creative Commons Licence conditions.

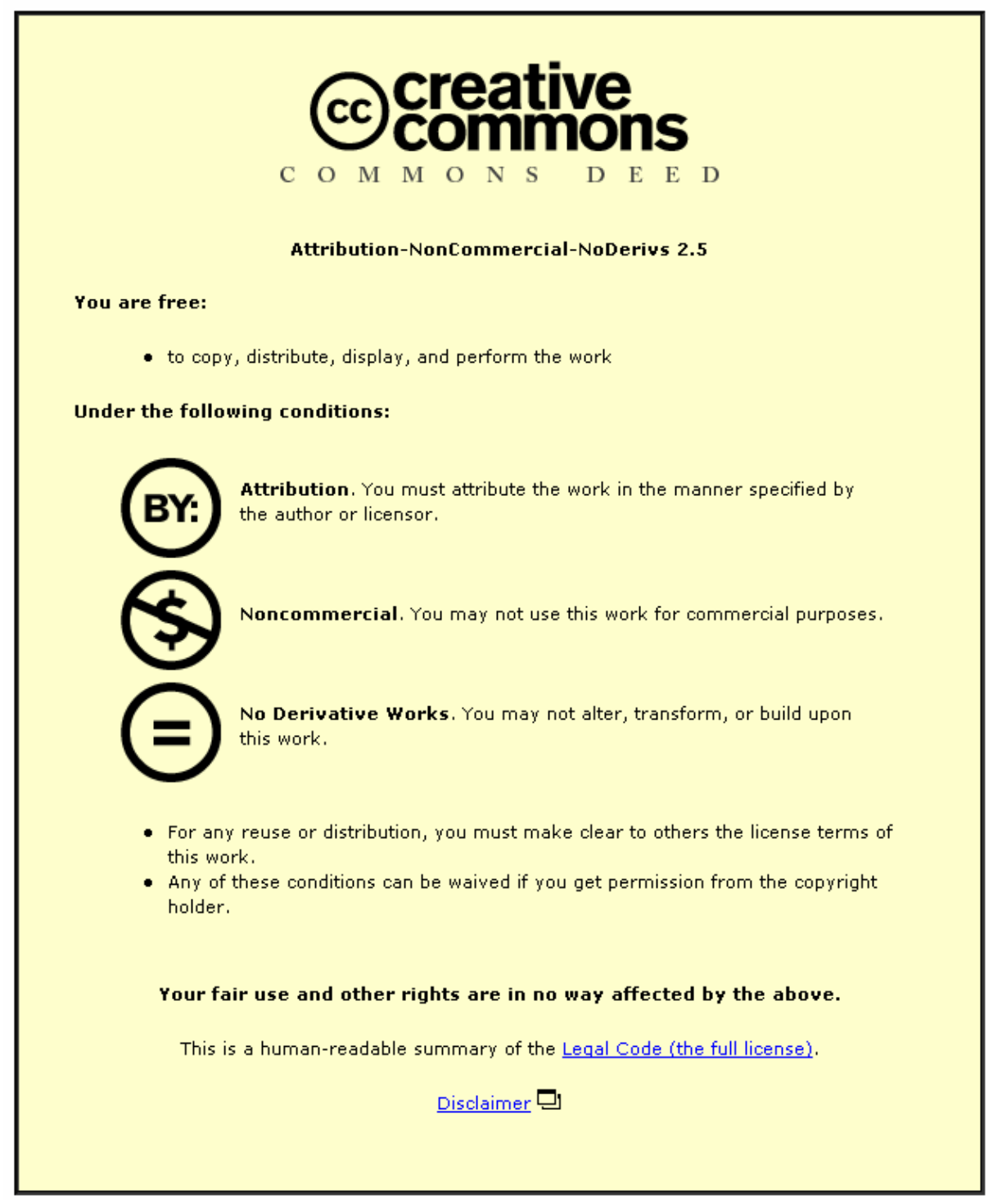

For the full text of this licence, please go to: http://creativecommons.org/licenses/by-nc-nd/2.5/ 


\title{
A Formal Asymmetric Synthesis of Both Enantiomers of the Erythrina Alkaloid 3-Demethoxyerythratidinone
}

\author{
Steven M. Allin, ${ }^{\mathrm{a} *}$ Guy B. Streetley, ${ }^{\mathrm{a}}$ Martin Slater, \\ Stella L. James ${ }^{\text {as }}$ and William P. Martin ${ }^{\mathrm{c}}$ \\ ${ }^{a}$ Department of Chemistry, Loughborough University, Loughborough, Leicestershire, LE11 3TU, England \\ ${ }^{b}$ BioFocus Discovery Limited, Chesterford Research Park, Saffron Walden, Essex CB10 1XL, UK. \\ ${ }^{c}$ GlaxoSmithKline Pharmaceuticals, Gunnels Wood Road, Stevenage, Herts SG1 $2 N Y$.
}

Abstract A formal asymmetric synthesis of both enantiomers of the Erythrina alkaloid 3-
demethoxyerythratidinone is reported through the application of a highly functionalised lactam template as
an $\mathrm{N}$-acyliminium precursor.

The genus Erythrina is common in tropical and subtropical regions and the alkaloids have been used in indigenous medicine. ${ }^{1}$ Members of the Erythrina family display curare-like and hypnotic activity, and a variety of pharmacological effects are associated with the erythrinane skeleton including sedative, hypotensive, neuromuscular blocking and CNS activity. ${ }^{2 a}$ Consequently there has been much interest in the synthesis of these alkaloids and derivatives (including pyrroloisoquinoline precursors) over recent years. ${ }^{2}$

3-Demethoxyerythratidinone, 1, was isolated from Erythrina Lithosperma in 1973 by Barton and co-workers. ${ }^{3}$ Despite being structurally one of the simplest of the Erythrina class of alkaloid, it was not until 1984 that Tsuda reported the first total synthesis, in racemic form, of this natural product. ${ }^{4}$ Almost a decade later this same group reported an asymmetric route to the enantiomeric form of the natural product, the so-called "enantio-(-)-3-demethoxyerythratidinone". ${ }^{5}$

We have recently concerned ourselves with the development of novel, efficient and stereoselective routes to complex heterocyclic targets by employing $N$-acyliminium intermediates in cyclisation reactions. ${ }^{6}$ In a recent publication ${ }^{6 a}$ we detailed a novel approach to an erythrinanelike ring system through the application of a Meyers chiral lactam template. We now wish to report the successful application of our methodology to construct a functionalised erythrinane ring system in a highly stereoselective manner, thus representing a formal asymmetric synthesis of both enantiomers of the natural product, 3-demethoxyerythratidinone.

Although the chiral lactams pioneered by Meyers have been widely utilised in asymmetric synthesis, ${ }^{7}$ to the best of our knowledge the present application, as a precursor in an $\mathrm{N}$ acyliminium mediated cyclisation reaction leading to erythrinane targets, represents a novel use of this popular chiral template. In order to access the more highly functionalised alkaloid skeleton 
we were required to prepare the protected keto-acid substrate 3 . This compound was readily accessed by enolate alkylation and subsequent ester group hydrolysis of the commercially available mono-protected diketone $\mathbf{2}$, as shown in Scheme 1.<smiles>O=C1CCC2(CC1)OCCO2</smiles><smiles>COC(=O)CBr</smiles>

2

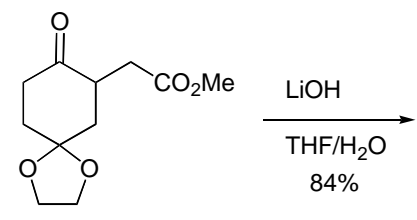

Scheme 1<smiles>O=C(O)CC1CC2(CCC1=O)OCCO2</smiles>

3

Our synthesis of the required lactam substrate $\mathbf{5}$ then followed similar methodology to that previously described by us, ${ }^{6}$ with the required $\beta$-aminoalcohol 4 prepared in $97 \%$ yield by reduction of the commercially available amino acid, 3-(3,4-dimethoxyphenyl)- $L$-alanine, with $\mathrm{LiBH}_{4}$ in the presence of $\mathrm{Me}_{3} \mathrm{SiCl}$ in THF for 24 hours at room temperature. Condensation of substrates 3 and $\mathbf{4}$ under Dean-Stark conditions in toluene for 48 hours gave a $63 \%$ yield of the desired lactam 5 as a single diastereoisomer (Scheme 2). The formation of a single product diastereoisomer of lactam $\mathbf{5}$ from the racemic keto acid $\mathbf{3}$ requires the epimerisation of the stereogenic centre adjacent to the ketone during the reaction, and this fact has been noted previously for similar substrates in the preparation of polycyclic lactams for use as $\mathrm{N}$ acyliminium precursors. ${ }^{6 a, 8}$

With 5 in hand, we turned our attention to the proposed asymmetric cyclisation. On treating lactam 5 with 3 equivalents of $\mathrm{TiCl}_{4}$ as Lewis acid activator at low temperature in dichloromethane for 20 hours we were pleased to isolate the tetracyclic product $\mathbf{6}$ in an excellent 92\% yield. Perhaps not unexpectedly, the cyclisation under strong Lewis acid conditions had been accompanied by concomitant deprotection of the ketal protecting group. Reducing the number of equivalents of the Lewis acid did not result in selective formation of the corresponding cyclisation product with the ketal group intact, and instead an inseparable product mixture was obtained. Indeed, since the removal of the protecting group did not hinder the immediate progress of our work, we favoured the use of excess Lewis acid to achieve clean and complete deprotection at this stage. ${ }^{1} \mathrm{H}$-NMR Analysis of the crude product mixture revealed the formation of a 10:1 mixture of product diastereoisomers.

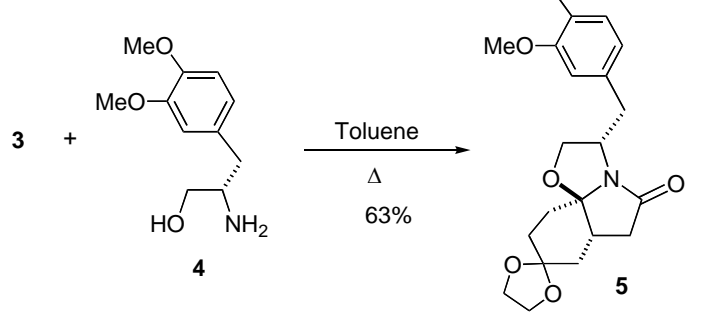

$[\alpha]_{D}=+56.1\left(\mathrm{c}=1.14, \mathrm{CHCl}_{3}\right)$

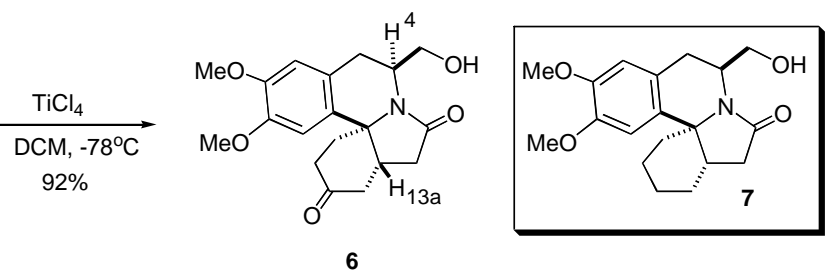

$[\alpha]_{D}=-53.4\left(\mathrm{c}=1.22, \mathrm{CHCl}_{3}\right)$

\section{Scheme 2}

The major diastereoisomer $\mathbf{6}$ was isolated by column chromatography. In our previous work on the synthesis of the related compound $\mathbf{7}$, prepared by analogous chemistry, we were able to determine the relative stereochemistry by X-ray crystallography. In this present case we were 
unable to obtain suitable crystals for X-ray, however the absence of an NOE between the protons at positions 4 and 13a supports the proposed structure; one would not expect a change in product stereochemistry to be favoured on simply introducing the remote protecting group in this current series. The stereochemical outcome of this cyclisation reaction can be rationalised using the same conformational model previously proposed by our group for related cyclisations. ${ }^{6}$ The presence of an asymmetric centre next to the iminium carbon may also act to influence the formation of the new chiral centre on cyclisation. If this were to be a contributing factor, one can appreciate that the aromatic ring approaches the planar acyliminium intermediate from the direction of least steric hindrance.

Removal of the pendant hydroxymethyl substituent (auxiliary) from the tetracyclic product $\mathbf{6}$ was achieved by application of a three-step procedure (Scheme 3). Dess-Martin periodinane oxidation of the primary alcohol proceeded in $93 \%$ yield to provide aldehyde $\mathbf{8}$. We then employed our favoured Rh-catalyzed decarbonylation protocol to access enamide $\mathbf{9}$ in $55 \%$ yield; a small amount of target compound $\mathbf{1 0}(6 \%)$ was also produced directly in this reaction. The auxiliary removal sequence was completed by catalytic hydrogenation of the crude mixture from the previous step to furnish the amidoketone $\mathbf{1 0}$ in $\mathbf{7 9 \%}$ yield.

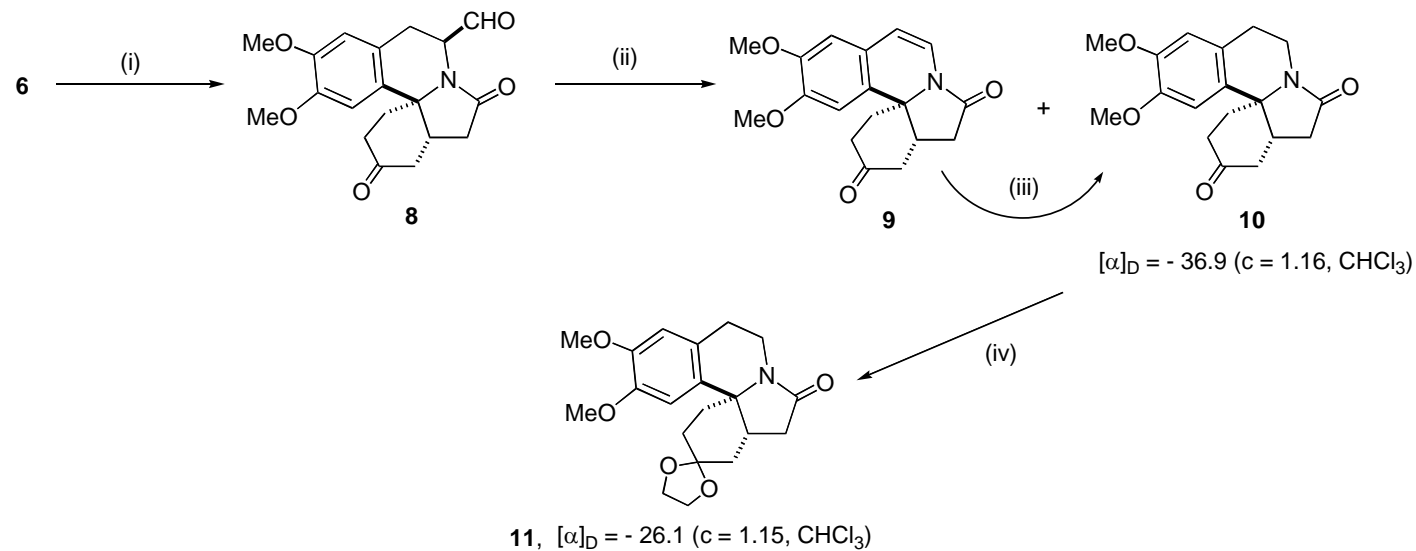

Scheme 3. (i) Dess-Martin periodinane, DCM; (ii) $\mathrm{Rh}\left(\mathrm{PPh}_{3}\right)_{2}(\mathrm{CO}) \mathrm{Cl}$, dppp, mesitylene, $\Delta, 4$ days;

(iii) $\mathrm{H}_{2} / 10 \%$ Pd-C, EtOH; (iv) ethylene glycol, $p$ TSA (cat.), toluene, $\Delta$.

The formal asymmetric synthesis of (+)-demethoxyerythratidinone, the natural enantiomer, simply required re-protection of the ketone functional group using ethylene glycol as shown in Scheme 3. Compound $\mathbf{1 1}$ has been converted by others to the natural product albeit in racemic form by a 4 -step sequence. ${ }^{4}$

The formal asymmetric synthesis of the unnatural enantiomer followed an identical synthetic route, beginning however with the enantiomeric form of the original amino acid substrate to access the required lactam substrate 12, which had the opposite optical rotation value to that obtained for lactam $\mathbf{5}$. Intermediate $\mathbf{1 3}$ gave an optical rotation of +39.6 , compared to -36.9 for compound 10. The enantio-target 14 , gave an optical rotation of +21.7 , compared to -26.1 for compound $\mathbf{1 1}$ (all measured at slightly altered concentrations).
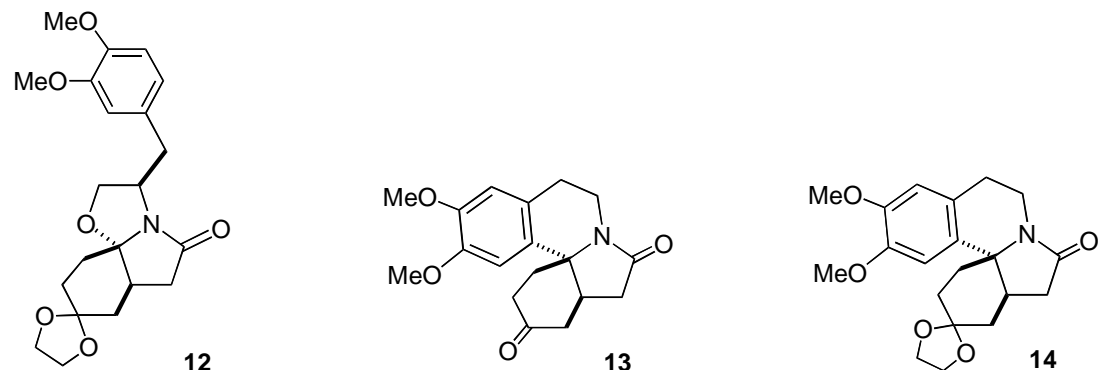
To summarize, we report the first synthetic application of our recently developed asymmetric $\mathrm{N}$ acyliminium cyclisation methodology in natural product chemistry. Our approach allows a facile and highly stereoselective formal synthesis of both enantiomers of the alkaloid 3demethoxyerythratidinone.

Acknowledgments: Loughborough University, Biofocus Ltd (joint studentship to GBS) and GlaxoSmithKline Pharmaceuticals (joint studentship to SLJ).

\section{References and Notes}

$\S$ - Present address: Charnwood Molecular Ltd., The Heritage Building, Beaumont Court, Prince William Road, Loughborough LE11 5GA.

1. Tanaka, H.; Tanaka, T.; Etoh, H.; Goto, S.; Terada, Y. Heterocycles 1999, 51, 2759-2764; Dyke, S.F.; Quessy, S.N. The Alkaloids; Rodrigo, R.G.A. Academic Press: New York, 1981, Vol. 18.

2. (a) Padwa, A.; Hennig, R.; Kappe, C.O.; Reger, T.S. J. Org. Chem. 1998, 63, 1144-1155 and references cited therein; (b) Rigby, J.H.; Deur, C.; Heeg, M.J. Tetrahedron Lett. 1999, 40, 6887-6890; (c) Rigby, J.H.; Hughes, R.C.; Heeg, M.J. J. Am. Chem. Soc. 1995, 117, 7834-7835; (d) Suda, Y.T.; Hosai, S.; Ishida, K.; Sangai, M. Chem. Pharm. Bull. 1994, 42, 204-213; (e) Lete, E.; Egiarte, A.; Sotomayor, N.; Vicente, T.; Villa, M.-J. Synlett 1993, 41-42; (f) Manteca, I.; Sotomayor, N.; Villa, M.-J.; Lete, E. Tetrahedron Lett. 1996, 37, 7841-7844; (g) Lee, Y.S.; Kang, D.W.; Lee, S.J.; Park, H. J. Org. Chem. 1995, 60, 7149-7152; (h) Lee, Y.S.; Kang, D.W.; Lee, S.J.; Park, H. Synth. Commun. 1995, 25, 19471956; (i) Lee, J.Y.; Lee, Y.S.; Chung, B.Y.; Park, H. Tetrahedron 1997, 53, 2449-2458; (j) Katritzky, A.R.; Mehta, S.; He, H.-Y. J. Org. Chem. 2001, 66, 148-152; (k) Garcia, E.; Arrasate, S.; Ardeo, A.; Lete, E.; Sotomayor, N. Tetrahedron Lett. 2001, 42, 1511-1513.

3. Barton, D.H.R.; Gunatilaka, A.A.L.; Letcher, R.M.; Lobo, A.M.F.T.; Widdowson, D.A. J. Chem. Soc., Perkin Trans. 1 1973, 874-880.

4. Tsuda, Y.; Nakai, A.; Ito, K.; Suzuki, F.; Haruna, M. Heterocycles 1984, 22, 1817-1820.

5. Hosoi, S.; Ishida, K.; Tsuda, Y. Chem. Pharm. Bull. 1992, 40, 3115-3117.

6. (a) Allin, S.M.; James, S.L.; Martin, W.P.; Smith, T.A.D. J. Org. Chem. 2002, 67, 9464-9467; (b) Allin, S.M.; Thomas, C. I.; Allard, J. E.; Duncton, M.; Elsegood, M.R.J.; Edgar, M. Tetrahedron Lett. 2002, 44, 2335-2337; (c) Allin, S.M.; Vaidya, D.G.; James, S.L.; Allard, J.E.; Smith, T.A.D.; McKee, V.; Martin, W.P. Tetrahedron Lett. 2002, 43, 3661-3663; (d) Allin, S.M.; James, S.L.; Martin, W.P.; Smith, T.A.D, Elsegood, M.R.J. J. Chem. Soc., Perkin Trans. 1 2001, 3029-3036; (e) Allin, S.M.; James, S.L.; Page, M.I.; Slawin, A.M.Z. Tetrahedron Lett. 1998, 39, 4905-4908.

7. Meyers, A.I.; Brengal, G.P. Chem. Commun. 1997, 1-8. (b) Groaning, M.D.; Meyers, A.I. Tetrahedron 2000, 56, 9843-9873.

8. Ragan, J.A.; Claffey, M.C. Heterocycles 1995, 41, 57-70; Ennis, M.D.; Hoffman, R.L.; Ghazal, N.B.; Old, D.W.; Mooney, P.A. J. Org. Chem. 1996, 61, 5813-5817. 